\title{
Congresos científicos latinoamericanos y estudios universitarios entre las expectativas de las maestras tucumanas, principios del siglo $\mathrm{XX}$
}

Latin American scientific congresses and universitaries studies among the expectations of the teachers of Tucumán, early twentieth century

Marcela Vignoli

Instituto Superior de Estudios Sociales - Universidad Nacional de Tucumán

- Consejo Nacional de Investigaciones Cientificas y Técnicas, Argentina

vigmarce@gmail.com

\section{Resumen:}

En medio de un clima cultural en el que se discutía ciencia y progreso en la provincia de Tucumán, algunas maestras manifestaron inquietudes por participar en los Congresos Científicos Latinoamericanos que se llevaban a cabo en la región en el cambio de siglo. Intentaremos determinar de qué manera la ciencia formó parte del horizonte de expectativas de un grupo de mujeres instruidas, las que además presionaron por continuar sus estudios superiores en otras provincias, hasta que se creó la Universidad provincial en 1914. Indagaremos los objetivos reales que tuvo esta institución respecto de la educación de las mujeres, contrastando con otras universidades del período. Este propósito nos llevará a explorar en libros de actas de asociaciones de índole cultural educativa donde estas mujeres tuvieron destacada actuación, así como en los documentos de creación de la Casa de Altos Estudios.

Palabras ClaVe: Educación femenina, Universidad, Ciencia, Asociacionismo, Cultura.

\begin{abstract}
:
The aim of this article is to analyze the concerns expressed by some teachers of Tucumán for participating in the Latin American Scientific Congresses that took place in the region at the end of the XIX century and the beginig of XX century. We will try to determine how science was part of the horizon of expectations of this group, who also pushed to continue their higher education in other provinces, until the provincial university was created in 1914. We will investigate the real objectives that had this institution regarding the education of women, contrasting with other universities of the period. This purpose will lead us to investigate in books of minutes of associations of educational cultural nature where these women had outstanding performance, as well as in the documents of creation of the House of High Studies.
\end{abstract}

KeYworDS: Women's education, University, Science, Associationism, Culture.

\section{INTRODUCCIÓN}

A principios del siglo XX, en pleno proceso de intensa expansión económica de base agroexportadora y modernización institucional que tenía lugar en la Argentina, el país solo contaba con las universidades de Córdoba (fundada en el período colonial por la Corona espaola y los jesuitas) y la de Buenos Aires, fundada en 1821 durante la gobernación de Martín Rodríguez. La posición de prestigio que ocupaban en la escena cultural era innegable y constituían, además de una promisoria entrada a la vida política, una vía segura de ascenso social para las nacientes clases medias que se engrosaban con el aporte inmigratorio. Se trataba de universidades esencialmente profesionalistas; en las cuales la matrícula se concentraba en las carreras de abogacía y medicina, las que auguraban un futuro tan rentable como prestigioso. Esta característica, que definía el perfil académico de ambas, iba en desmedro tanto del desarrollo de las ciencias en su seno como de la formación de educadores para todos los niveles de la enseanza. Por el contrario, las dos universidades que surgen a principios del siglo XX con propósitos diferentes a las mencionadas, la de La Plata (fundada bajo la égida del Estado nacional en 1905) y la de Tucumán (nacida como institución provincial pero nacionalizada en 1921) aspiraban articular la formación técnica y los desarrollos científicos con la divulgación a gran escala (la "extensión universitaria" o "extensión popular") de conocimientos "prácticos" orientados a resolver 
problemas de la producción y de la vida social en general. En ese marco, incluían entre sus incumbencias la problemática pedagógica en un momento histórico en el que las mujeres consolidaban en el espacio público su rol como educadoras (Barletta, 2011; Southwell, 2014).

Ese aumento de la participación de educadores también se puede advertir a partir del estudio de las asociaciones y de la acción gremial docente durante las primeras décadas del siglo XX, que ha llamado la atención de la historiografía argentina en años recientes revelándose como un terreno fructífero para estudiosos interesados en la historia social de la educación (Ascolani, 1998, 2010; Martínez Trucco, 2004; Gindín, 2008, 2010, 2015; Acri, 2012; Richard-Jorba, 2013). Sin embargo, hay una coincidencia en que a pesar de la feminización del magisterio a principios del siglo XX, las mujeres habrían estado ausentes del mundo asociativo. Según Julián Gindín (2010), quienes creaban las asociaciones eran por lo general personas con cargos jerárquicos dentro del magisterio, y, estos roles rara vez eran ocupados por mujeres, de modo que era otro motivo para quedar fuera del ámbito asociativo. Sin embargo, el autor también considera que "las primeras asociaciones fueron un espacio (limitado, pero espacio al fin) de afirmación femenina en el espacio público" (Gindín: s/f).

A principios del siglo XX, ese aumento de la participación de educadores se vio reflejado en la creación de una asociación que nucleaba a maestras y maestros de la provincia de Tucumán (Vignoli, 2015). El "Círculo del Magisterio", creado en 1905, constituyó una asociación que canalizaba una serie de propósitos e inquietudes que incluyeron también la continuidad de estudios superiores y el interés por la ciencia.

En 1906, una maestra propuso que esta asociación enviara “[...] de entre sus socios, delegados al Congreso Científico Latinoamericano que se celebra todos los años” y que "proporcione los medios para continuar una carrera especial a los maestros socios que revelaren condiciones sobresalientes en alguna rama del saber”. ${ }^{1} \mathrm{La}$ propuesta fue de Margarita Todd, ${ }^{2}$ quien refería a los Congresos Científicos Latinoamericanos que se habían celebrado en Argentina (1898), Montevideo (1901) y Río de Janeiro (1905). Este último había contado con la participación de 839 miembros provenientes de 17 países. En esa oportunidad se presentaron un total de 120 trabajos correspondientes a las diferentes secciones en que se había dividido el congreso: matemáticas, ciencias físicas y químicas, ciencias naturales antropológicas y etnológicas, ingeniería, ciencias médicas e higiene, ciencias jurídicas, ciencias sociales, ciencias pedagógicas y agronomía y zootecnia (Ribeiro, 2002). En la reunión de Río de Janeiro se había decidido que el próximo evento, a realizarse a comienzos de 1908, tendría el carácter de panamericano y que su sede sería Chile. ${ }^{3}$ Evidentemente, la intervención de Margarita aludía a la participación en este futuro congreso, y formaba parte de uno de los objetivos que debía plantearse la asociación tucumana de maestros como forma de insertarse en un circuito que discutía sobre educación, ciencia y avances en la salud. Probablemente, a sus oídos llegaron referencias del congreso celebrado en Río de Janeiro en 1905, ya que participaron como delegados de Argentina dos tucumanos, el médico Eliseo Cantón y el ingeniero Carlos Wauters. ${ }^{4}$ Por otra parte también se presentó la memoria de viaje de Antonio Carlos Simmoes Da Silva, en la que la estancia en Tucumán tiene un lugar destacado (Ribeiro, 2002, pp. 109-141). Es muy probable que estas noticias circularan una vez terminado el congreso y tentaran a los maestros que buscaban mejorar su profesión a través del debate acerca del sistema educativo, los métodos de enseñanza, y las posibilidades de la educación para las mujeres, ya que en este congreso la sección pedagogía contó con la publicación de ocho trabajos, destacándose en esta sección la participación de mujeres. ${ }^{5}$

En nuestro país el campo del normalismo se ha visto enriquecido por una serie de investigaciones que indagan en el lugar de las maestras tanto dentro como fuera del aula. Sus prácticas de consumo, sus experiencias asociativas de variada índole, la relación entre maestras y maestros con el Estado a partir de su rol de funcionarios, las prácticas de índole cultural del magisterio, sus expectativas en vínculos internacionales así como su vida amorosa, entre otros temas, han sido objeto de análisis logrando abarcar diferentes geografías provinciales (Lionetti, 2007; Caldo, 2013, 2014; Fiorucci, 2012, 2018; Billorou, 2016). 
El propósito de esta investigación es analizar el sentido que tuvo para las maestras, así como para mujeres instruidas que no se desempeñaron como tales pero que habían pasado por el sistema educativo, la posibilidad de continuar sus estudios superiores, así como participar en congresos científicos internacionales.

Intentaremos responder a los siguientes interrogantes ¿Qué representaba para estas maestras la posibilidad de participar de un evento de estas características? ¿Cuál era la idea de ciencia que circulaba entre los maestros tucumanos y en la sociedad tucumana de principios de siglo?

Nuestra hipótesis sostiene que probablemente las intervenciones de esta maestra tucumana expresaban las preocupaciones intelectuales y culturales de una época, de la que también formaron parte las mujeres instruidas, en la que uno de los horizontes lo constituía el conocimiento científico con miras a la creación de una futura universidad provincial. ${ }^{6}$ Además, es posible contrastar esta realidad con estudios de caso de otras latitudes. Por ejemplo, Susana García (2006) ha analizado la trayectoria de algunas mujeres argentinas pioneras en actividades científicas de principios de siglo en la región metropolitana. Por su parte, Natalia Priego exploró las expectativas en educación superior que tuvo una maestra mexicana como fue Petra Martínez (Priego, 2011).

\section{El ingreso de mujeres en un ambiente de sociabilidad literaria}

La cuestión de la participación de las mujeres en el mundo educativo constituía un tópico de discusión convocante en Tucumán, como quedó documentado en los primeros nmeros de las revistas de la Sociedad Sarmiento (Vignoli, 2011; 2015a). ${ }^{7}$ En efecto, a principios de la década de 1880 tanto hombres como mujeres vinculados al mundo educativo escribieron artículos tratando de definir cuáles serían las mejoras que debían hacerse a la educación de "las niñasă fin de inculcarles una serie de valores, que en el caso tucumano también pretendían seguir una pauta patriótica.

Si bien las alusiones a cambios transgresores en las costumbres femeninas, así como las referencias a la adquisición de derechos políticos, provocaban el rechazo masculino en la voz de los cronistas, es posible percibir una actitud más tolerante ante las experiencias de incorporación de la mujer al mundo del trabajo, así como respecto a su acceso al sistema educativo.

Sobre esta cuestión no existía, sin embargo, una mirada unívoca, y comenzaban a escucharse opiniones que cuestionaban la pretendida la inferioridad "natural" de la mujer que justificaba su subordinación jurídica frente al hombre: "Perseguir en esta época los derechos de la mujer y luchar generosamente para que ella los reivindique ante las sociedades modernas no es una quimera". De esta forma comenzaba el artículo de Bernabé García, ${ }^{8}$ quien había disertado en la Sociedad Sarmiento a fines del año 1882. García repasaba el lugar de la mujer a lo largo de la historia adhiriendo a la idea de que el rol ocupado en ese momento era considerablemente mejor que en el pasado.

Sin embargo, respecto de la adquisición de derechos políticos, García se oponía tajantemente a la participación femenina mientras no contase con una educación que la habilitara para asumir "conscientemente" tal responsabilidad. Consideraba que su influencia podía ser poderosa, "grabando en el corazón del niño, con su cariño de madre, el sentimiento de justicia, el respeto a la ley y a las instituciones", y no negaba su futura participación en actividades y funciones que hasta entonces habían sido vedadas al "sexo débil".?

Hacia 1893 registramos la presencia de la sección "Colaboración del Bello Sexo" en El Tucumán Literario, que alentaba la participación femenina en el entendimiento que la mujer tucumana debía estar representada en la literatura y el periodismo.

Algunas de las autoras de las colaboraciones eran docentes y desempeñaban su profesión en el medio provincial. Los artículos reflexionaban sobre la necesidad de instrucción de la mujer, lo que reportaría beneficios a la sociedad, así como también sobre su rol en la docencia, incluyendo cuestionamientos a su 
pretendida inferioridad intelectual frente a los varones. Sin embargo, a la hora de evaluar los fines de esa instrucción, las mujeres no lograban desmarcarse de su función asociada a la maternidad. Así, en una de las notas se afirmaba:

"[...] vemos que poseen ambos iguales facultades, superiores, si se quiere en la mujer, pues ésta desde niña discurre, piensa, reflexiona y comprende más pronto una explicación cualquiera que un niño [...] yo quiero que su educación e instrucción sean más extensas para que así sepa desempeñar debidamente el triple papel de hija, madre y esposa que le está encomendado, y que por lo defectuoso de nuestra educación no sabemos cumplir [...]”.10

La respuesta a esta nota no tardó en aparecer en las mismas páginas de El Tucumán Literario: "Si la mujer va a la universidad, al congreso, etc. ¿El hombre amamantará nuestros hijos, los educará? La misión de la mujer es una y la educación de la sociabilidad moderna no es suficiente para trocar ese principio nacido con ella. ${ }^{11}$

No obstante la persistencia de estos prejuicios, como parte de un proceso irreversible la mujer había invadido el ámbito educacional, puerta de entrada para avanzar hacia otras profesiones y ocupaciones en el espacio público y que le permitiría ensanchar su horizonte de expectativas en un momento en el que en la provincia se discutía la posibilidad de contar con estudios superiores.

\section{La configuración de un ambiente de discusión científico en Tucumán de principios de siglo y la participación de algunas maestras}

Hacia 1904, la Sociedad Sarmiento desplegaba en el medio provincial una serie de actividades que la convertían en un ámbito cultural de prestigio. Con aproximadamente 800 socios, asistían a la biblioteca un elevado número de personas, ${ }^{12}$ se realizaban periódicamente veladas literario musicales -por lo general en el Teatro Belgrano-, se organizaron 24 conferencias en el ciclo denominado "los lunes de la Sarmiento", con oradores del medio y externos de renombre, ${ }^{13}$ y sus reuniones se habían dividido en "secciones", como ya se indicó. Los datos son aún más elocuentes si los comparamos con la recientemente creada Biblioteca Alberdi, que pretendía disputar a la Sarmiento el liderazgo en el terreno cultural. ${ }^{14}$ De cualquier modo, estos datos demuestran la vitalidad de la sociedad tucumana en materia cultural y el empeño con que la Sarmiento y otras asociaciones llevaron adelante iniciativas en este terreno. ${ }^{15}$

Pero el proyecto más ambicioso en la dirección de promover la educación superior en la provincia fue la de los "cursos libres", que fuera propuesto por Julio López Mañán en julio de 1904. El proyecto, que también contemplaba la creación de un archivo de documentos antiguos "para facilitar estudios históricos", fue sintetizado en los siguientes términos:

"La Sociedad Sarmiento procurará que todos los año se dicten en su local uno o más cursos libres sobre ciencias o letras, que en cuanto sea compatible con la enseñanza desarrollen en los oyentes las aptitudes de investigación y de crítica [...] la inscripción en la matrícula será pública y sin limitación de cursos, debiendo solamente el inscripto abonar por ella un derecho de $4 \$$ por cada curso [...] Se hará constar además que los que en cada materia hayan sido designados personas que se hubiesen distinguido por su preparación y que hayan obtenido mayor asistencia serán propuesto a la Asamblea por la Comisión Directiva con el carácter de socio honorario". ${ }^{16}$

Se planeaba el comienzo de los cursos (al que podrían asistir las mujeres) para 1905, pero comenzaron a dictarse en agosto de 1906, ${ }^{17}$ ocasión en la que Juan B. Terán dejó en claro que no eran sino un ensayo preparatorio, un anticipo de algunas actividades que se desarrollarían desde la futura universidad:

"Participa este ensayo de las funciones de la extensión universitaria como se llama en Inglaterra a la aproximación de los institutos de instrucción superior a las clases más numerosas de la sociedad para abarcar en sus beneficios a la que no ha tenido la fortuna de hacer sus cursos oficiales, para difundir las investigaciones y las verdades científicas especiales y superiores [...]

[...] Este régimen de libertad, la concurrencia abierta tanto para los que enseñan como para los que aprenden es lo que hace la nobleza de estos cursos populares lo que vivifica su ambiente y les da su resorte sensible. No llevan a ningún título ni 
preparan para ninguna profesión -no se proponen sino la mayor cultura abstracta, la mayor difusión de conocimientos por lo que ellos mismos significan, por la propia virtualidad que contienen. Pero su tendencia es de enseñanza superior. Aspira así a completar no a rivalizar [...] Toda sociedad, y la nuestra es ya una sociedad con los procesos complejos de la vida moderna necesita enriquecerse con centros científicos que desempeñen la función progresiva en su vida espiritual [...]

Se hospedan ahora los cursos libres en esta Escuela Normal por concesión del gobierno de la Nación a la intercesión del gobierno de la Provincia, pero están destinados a darse junto a nuestra biblioteca, cuando se levante la casa que ha de formar su hogar permanente y seguro la Sociedad Sarmiento. Con esta forma rudimental de los cursos libres que han de cumplimentarse en una organización y en un mayor desarrollo, con su biblioteca de 15.000 volúmenes que esfuerza amplificar sin demora, con el Instituto de Bacteriología creado ya, hermosa promesa de aplicaciones prácticas y de ensayos teóricos y después con el Museo de historia americana e historia natural y regionales, la Escuela de Bellas Artes, también proyectada, quedan enumerados los elementos que han de federarse en la futura universidad de Tucumán”. 18

La crónica de El Orden decía respecto de la concurrencia a la inauguración: "No sólo asistió una gran parte de nuestra juventud estudiosa. Asistieron también, numerosos caballeros conocidos y muchas de nuestras educacionistas más inteligentes, atraídas por la feliz iniciativa de la Sarmiento". ${ }^{19}$

A principios del año siguiente, los cursos libres de la Sociedad Sarmiento habían llamado la atención de la prensa de la ciudad de Buenos Aires, la que comparando estos cursos con los dictados por otras Sociedades del país ${ }^{20}$ y con las tradiciones belga e inglesa, reflexionaba sobre la duración y efectividad de los mismos, para luego evaluar las diferencias que existían entre estos y los cursos universitarios,

“[...] aquellas sociedades como la asociación sarmiento (de Tucumán), que han procurado hacer palpables las ventajas de la extensión logrando honrosísimos éxitos [...] según los datos que dicha asociación me ha suministrado, comprendieron tan solo 4 conferencias los cursos que [...] dictaron Ubaldo Benci y Jaimes Freyre. El curso del Dr. García [...] se ha ajustado, en cambio, a un programa de cinco conferencias. Nada debe extrañarnos la prudente limitación del número de sesiones, destinadas a un tema circunscripto cuando se trata de un auditorio forzosamente heterogéneo. [...] Tropezamos con una objeción formulada a menudo a la extensión Universitaria, que no es posible formar alumnos con seis conferencias [...] La extensión no pretende formar alumnos, su único propósito es elevar el nivel de la vida, creando en todas las clases un interés cada vez mayor por los asuntos que elevan la mente, acrecientan el buen gusto artístico y literario o conducen a la prosperidad y a la educación moral por el trabajo". ${ }^{21}$

En 1907, los cursos libres estuvieron a cargo del Dr. Luis Poviña, el Ingeniero Benjamín Reolín, el Dr. Juan B. Terán y el Ing. Rogelio Costanti. ${ }^{22}$ Durante 1908 se registró un curso libre, el que desde octubre a noviembre dictó el director de la Escuela Normal de Monteros, José M. Monzón, quien abordó en cinco conferencias el tema "Filiación científica del descubrimiento de América". Hubo, sin embargo, una serie de conferencias que adoptaron el formato de cursos libres, como los dictados por el historiador David Peña, que abordó en tres conferencias consecutivas las personalidades de Rivadavia, Dorrego y Alberdi y que llegó a congregar a 400 personas según la prensa. Pero es posible encontrar otros sentidos a la presencia de David Peña, como también a la de otras figuras de la intelectualidad argentina que comenzaron a visitar con asiduidad a Tucumán en un momento en que comenzaba a tomar forma el proyecto universitario. De algún modo esas visitas constituían un apoyo explícito a un movimiento que, poniendo de relevancia a Tucumán como uno de los centros de cultura más importantes del interior, concluía en que la creación de la universidad era un imperativo cuya materialización no podía postergarse.

En octubre de 1909 Juan B. Terán, que a la sazón ocupaba la vicepresidencia de la Cámara de Diputados tucumana, presentó el proyecto de creación de la universidad provincial. Y El Orden salía en su apoyo poniendo el acento en las necesidades regionales que una universidad localizada en Tucumán podía servir:

“Tucumán merecería ser el asiento de una universidad Nacional con inmensas ventajas para sus hijos y para los demás de las provincias del norte. Si se ha estimado conveniente fundar un establecimiento de esa naturaleza en la ciudad de La Plata, lo que quiere decir a las puertas de Buenos Aires, resalta a la vista la justicia y la conveniencia de tener una Universidad en Tucumán [...] Económica e intelectualmente las demás provincias giran alrededor de esta ciudad. Mucha gente pobre del norte o de aquí mismo no sacrificaría a las exigencias de la vida cara de Buenos Aires, jóvenes preparados, jóvenes de provenir indiscutible para la patria.". 23 
Mientras tanto, continuaban las visitas de personalidades vinculadas al ambiente universitario nacional y a la investigación científica, quienes disertaron sobre diferentes tópicos: el explorador austríaco Max Neumayer se refirió a los "Factores principales del progreso agrícola-ganadero argentino"; el poeta y literato Carlos Alberto Leuman habló sobre los "Hombres y sucesos del año 52'"; el doctor Carlos Rodríguez Etchart, de la Universidad Nacional de La Plata, disertó sobre "La fe religiosa y su enseñanza", mientras Rodolfo Alcides Rivarola, decano de la Facultad de Ciencias Físicas de La Plata y a la vez de la Facultad de Filosofía de la Universidad de Buenos Aires, dio una conferencia sobre "La experimentación en la ciencia y en la vida". Pese a los sólidos apoyos con que contaba el proyecto universitario de Terán y del equipo dirigente de la Sarmiento en el plano local, este tipo de avales de personalidades como la de Peña eran imprescindibles frente a ciertos cuestionamientos a la idea, tal la que formulaba el diario La Nación de Buenos Aires, contrario a la creación de la universidad provincial. En dicha oportunidad Terán defendía el proyecto reivindicando el derecho de las provincias y las regiones a contar con sus propias instituciones de altos estudios:

"Todas las del país han empezado por ser provinciales. La de Buenos Aires fundada por el gobierno de esa provincia. La de
Córdoba no puede ser referida a estas ideas dada la época de su fundación pero fue una obra regional.
El señor Ministro de Instrucción Pública ha expresado ese pensamiento exacto de política educacional: La nación no debe
fundar universidades, debe fomentarlas, donde se haya demostrado capacidad para tenerlas y sostenerlas. No se puede
aceptar en forma alguna la opinión de que el país debe limitarse a las que se dicen históricas. ¿De dónde surgiría esa
incapacidad constitucional de las provincias? Son creaciones de este género, concebidas con justicia y mesura las que
pueden causar la liberación de las provincias. Causarían la liberación verdadera, la económica, puesto que lo que hace
verdaderamente fecundas y progresistas las industrias es el trabajo científico [...] Hay un interés nacional en que se
investigue sabiamente nuestro trabajo agrícola e industrial. No podrá decirse la palabra definitiva y segura sobre el porvenir
económico del norte sin que se hayan escrutado pacientemente sus problemas. ¿Esperaremos que lo hagan las universidades
de Córdoba o de Buenos Aires?". ${ }^{4}$

En efecto, la universidad provincial no sólo significaría un centro de estudios orientado a problemáticas regionales, sino que lograría atenuar la fuga de estudiantes a las universidades de Córdoba y Buenos Aires. Y tenía, como advirtió María Celia Bravo, "un propósito de carácter político y estratégico [...] destinado a restablecer una suerte de equilibrio político perdido por el crecimiento económico y demográfico del litoral" (Bravo, 2007, p. 47).

En mayo de 1910, la publicación Archivos de Pedagogía y Ciencias afines de la Universidad de La Plata destacaba que el plan de universidad provincial tenía características similares al de La Plata, "plan integral, vasto, humano, científico y moderno”, al tiempo que refería al norte argentino en los siguientes términos: "Tucumán con las provincias que la limitan constituye un laboratorio único en el país por sus problemas sociológicos, su vida fabril [...] la nueva casa de estudios superiores, radicada en el centro norte del país, [...] será un centro de vinculación intelectual y alta cultura moral [...]”. 25

La relación forjada entre los promotores de la universidad provincial y la Universidad Nacional de La Plata era evidente y se estrechaba día a día. En julio de 1910 repitió su visita a Tucumán Rodolfo Alcides Rivarola, decano de la Facultad de Ciencias Físicas de La Plata, quien disertó sobre un tópico vinculado directamente con el proyecto universitario, "Algunas ideas sobre la enseñanza superior en la República”, en realidad un trabajo pormenorizado sobre los distintos aspectos del proyecto tucumano.

"Los institutos científicos que ya posee Tucumán son indicio que esta ciudad será el asiento de una futura universidad nacional [...] Una ciudad en la cual viven con fecunda vida dos importantes bibliotecas, un colegio nacional, una escuela normal, una escuela agronómica del azúcar, un instituto de bacteriología e higiene, que ha creado hospitales atendidos con los mejores medios que alcanza el progreso de la ciencia, que está rodeada de maravillosos ingenios con los últimos perfeccionamientos del arte industrial, que es a la vez centro que irradia vías férreas, al norte y al oeste [...]” ${ }^{26}$

En 1911 y luego de casi dos años de ausencia, los cursos libres organizados por la Sociedad Sarmiento fueron recobrando su ritmo y prestigio, pero con la incorporación de los idiomas a las temáticas que hasta ese momento habían formado parte de la oferta académica. Bajo la denominación de "lenguas vivas" comenzó el 
dictado de francés e inglés en un total de ocho clases y con un cupo de 12 alumnos por curso. También Juan B. Terán dictó un curso en que proponía una "Lectura sobre el Código Vélez y el Código Civil”. Completaba la oferta de ese año una "Lectura sobre fuerzas perdidas en Tucumán", un curso sobre el potencial hidrográfico de la provincia, a cargo del Ing. Manuel J. Victoria. Al año siguiente se continuó con el impulso dado a los cursos, y a los idiomas se sumó un curso sobre "Contabilidad práctica", uno de los más extensos, dictado por el Sr. A. Coca Padrós. Otra de las novedades de ese año fue el dictado de un curso libre por parte de personal de la Estación Experimental. El grupo, dirigido por el Subdirector Arthur Rosenfeld, organizó una serie de charlas que giraron en torno a la plantación de la caña, el cultivo, la elaboración y la influencia de la selección de variedades. Completaron este tipo de actividades un curso del profesor José R. Fierro que se denominó "Moral Cívica", otro del doctor Abraham de la Vega, "Historia de la Civilización", mientras que Ricardo Jaimes Freyre habló sobre "Historia de la literatura castellana".

En ese mismo año, en junio, la Cámara de Senadores de la provincia aprobaba el proyecto de creación de la Universidad provincial, que había permanecido casi dos años y medio sin tratamiento contando con la media sanción de la Cámara de Diputados desde fines de 1909. Al año siguiente el gobernador Ernesto Padilla designó el Consejo Superior, integrado por Juan B. Terán, Miguel Lillo, José I. Aráoz, Guillermo Paterson, Ricardo Jaimes Freire, Arturo Rosenfeld, Miguel P. Díaz, Estergidio de la Vega, Alejandro Uslenghi, José Padilla, Juan Chavanne y José Benito González, todos miembros de la Comisión Directiva de la Sociedad Sarmiento. El Consejo Superior eligió rector a Juan B. Terán a fines de $1913 .{ }^{27}$ Pocos meses después comenzó el dictado de los primeros cursos de la nueva universidad, que se inauguró oficialmente el 25 de mayo de 1914.

\section{Las mujeres instruidas en el proyecto universitario de Tucumán}

El surgimiento de una nueva concepción sobre los estudios superiores en la Argentina, opuesta al profesionalismo y a la enseanza verbalista dominantes que se materializó con la creación de la Universidad Nacional de La Plata, cuyo primer Presidente fue Joaquín V. González, a la sazón Ministro de Justicia e Instrucción Pblica. La nueva universidad no sería una réplica de las doctorales de Córdoba y Buenos Aires. En ella se articularían armónicamente la enseñanzala investigación científica basada en procedimientos experimentales con orientaciones "prácticas" tendientes a solucionar problemas candentes de la sociedad.

Esta concepción también se expresó en el movimiento intelectual que precedió al surgimiento de la Universidad de Tucumán. El proyecto de ley de creación de la nueva casa de estudios - gestado en el seno de la Sociedad Sarmiento en la primera década del siglo- fue presentado en Octubre de 1909 por Juan B. Terán (quien comenzaba su segundo período como legislador ocupando la vicepresidencia de la Cámara de Diputados de la provincia) y reproducía, adaptado a las particularidades regionales.

En efecto, las características que el ambiente natural, la historia y el potencial productivo de las provincias norteñas, en particular las derivadas de su principal actividad económica, la azucarera, signaban el proyecto tucumano, que otorgaba un lugar de privilegio a la formación de químicos e ingenieros industriales. Del mismo modo, el concepto de "extensión" aparece dominante en ambas concepciones, inspiradas por las experiencias anglosajonas, en primer lugar las de las universidades norteamericanas, aunque los más recientes desarrollos e innovaciones de las universidades alemanas, francesas e inglesas también estaban considerados.

Entre las características que compartían las universidades de La Plata y Tucumán (y que las distinguían de las de Córdoba y Buenos Aires), se planteaba la necesidad de incorporar a su currícula los estudios pedagógicos. En el caso de La Plata se pretendía: "ensanchar el campo experimental en los estudios destinados a formar el profesorado común, secundario y superior de la República” (González, 1935:205) considerándose que la concurrencia femenina constituiría uno de los caracteres más peculiares de la Universidad. Para Joaquín V. González, 
"[...] el horizonte de acción social de la mujer ha sido muy limitado en nuestros pueblos latinos, y apenas se sospechaba la posibilidad de verla ocupar hoy una vasta porción del campo del monopolio masculino [...] se ha notado además, en la experiencia escolar de algunos años y en los estudios más intensos de psicología y fisiología humanas, que ella es adaptable a la mayor parte de las ocupaciones en los más perfeccionados servicios públicos del estado, de las compañías o empresas privadas, pueden ser desempeñadas por mujeres, con ventajas económicas y técnicas indudables [...] La Universidad no podía cerrarle sus puertas en un país libre [...] Maestras y alumnas en nuestra universidad son bienvenidas [...] con su concurso e influencia dulcificadora sobre las costumbres, será mucho más fácil realizar ese ideal de enseñanza moral por la sociabilidad y el compañerismo en la vida universitaria [...]" (González, 1935, pp. 219-220)

La creación, en 1914, de la Facultad de Ciencias de la Educación de La Plata era coherente con esa declaración de principios, que por otra parte asumía como un valor positivo las transformaciones que habían llegado con el cambio de siglo.

En la sección pedagógica, destinada a la formación de profesores secundarios, se admitió la inscripción de maestros normales, con clasificación sobresaliente en el último curso y la aprobación de algunas materias de quinto año del colegio secundario. Los estudios pedagógicos constituyeron una vía importante de acceso a la universidad para las mujeres y sectores de orígenes más modestos y de distintas localidades de la provincia de Buenos Aires y del interior del país.

En lo que hace a la Universidad de Tucumán, la creación de la Escuela Pedagógica importaba otros matices. Para Juan B. Terán, la "enseñanza vocacional” no era extraña a la Escuela Normal y justificaba la incorporación de algunas materias como "economía doméstica" y "trabajos manuales", que contribuirían a hacer menos especialista pero más "amplia y útil” las capacidades del maestro. Así éste "estará más habilitado para transformar los métodos librescos, y sustituirlos por los objetivos que enseñan a descubrir en la naturaleza los conocimientos” (Terán, s/f, pp. 87-88)

La "realidad", la "práctica", la "vida", la "naturaleza" son los ámbitos a los que Terán remite para el logro de una formación acorde con las necesidades de los hombres y las mujeres comunes, para los cuales la Universidad de Tucumán instrumentará las actividades de "extensión popular" y los "cursos nocturnos para obreros". Para el primer rector de la universidad tucumana la Escuela Pedagógica era un hogar de trabajo, "de alegría", donde se llevaba a cabo una de las "pasiones más grandes", como era la formación "del carácter y del corazón de los niños". Y continuaba:

"Tal es la función que estais llamadas a llenar en adelante, señoritas maestras, y mientras os despedimos, reparad una y otra vez que más que ilustración necesitais fe y amor, que más que tarea iréis a cumplir una misión, que más que cerebros se os entrega corazones e instintos -que la naturaleza es el libro mayor, que la nación necesita hombres sanos, alegres y generosos, y mujeres buenas, seguras de si mismas y de sus casas, obreras también de la grandeza moral y material a que aspiramos”. (Terán, s/f, p. 90).

Estas ideas eran compartidas por la Directora de la Escuela, Otilde B. Toro, quien en su primer informe explicaba los beneficios de la adecuación del plan de estudios:

\footnotetext{
"La incorporación de los programas de Agricultura, Higiene infantil, Trabajo manual y Economía doméstica, tenían que causar una transformación importante en la escuela primaria y en la actividad de la maestra. Por lo que atañe a la primera, se ha practicado rumbos nuevos al porvenir de la juventud abriendo grandes picadas en la rutina escolástica y con respecto a la maestra, se ha dado un gran paso inicial en el camino de la rehabilitación de la mujer como factor específico del progreso material. Hemos comenzado a amasar la Creta de donde saldrá la "New Women" de Tennyson, amoldada al sano y rico ambiente americano, donde la profilaxis didáctica de los nuevos y racionales planes de estudio habrá realizado la extirpación de los rancios prejuicios. Estudiando simultáneamente música y agricultura, moral cristiana y economía doméstica, imbuyéndose de la retórica y adiestrando el ojo y la mano en la manufactura; yendo con el mismo amor y provecho al conservatorio y a la chacra, la mujer argentina discretamente y eludiendo los excesos libertarios que caracterizan al feminismo de Stuart Mill, habrá abolido el formulismo universal, que, al esclavizarla, al subordinarla, se opone al progreso de la humanidad". (Terán, s/f, pp. 222-223).
}

Quizás el ambiente tucumano, una sociedad con un extendido campesinado cañero y un no menos importante sector de la población que proveía de trabajo asalariado a ingenios y fincas cañeras, haya determinado en cierto modo este proyecto, que no dejaba de poseer las connotaciones civilizatorias y 
moralizantes que orientaron las políticas hacia los sectores populares de la élite tucumana en la segunda mitad del siglo XX. Ese era el sentido de la "función social" que inexorablemente debía cumplir la casa de altos estudios.

\section{La experiencia de las mujeres en los años fundacionales de la Universidad de Tucumán}

La Universidad se inauguró oficialmente en un solemne acto que tuvo lugar en los jardines de la Escuela Sarmiento el 25 de mayo de 1914. Junto al Gobernador Padilla, los presidentes de las cámaras de senadores y diputados, el presidente de la Corte Suprema, el rector Terán y el Consejo Superior de la Universidad, se hicieron presentes representantes del Ministerio de Instrucción Pblica de la Nación, de las provincias de Catamarca, Jujuy, Salta y de las Universidades de Córdoba y Buenos Aires. Pero la figura de mayor relevancia que asistió para expresar su adhesión a la creación de la institución fue sin dudas, Joaquín V. González, presidente de la Universidad de La Plata

La institución comenzó a funcionar con el Departamento de Bacteriología, la Oficina de Química de la Provincia y la Escuela Sarmiento que asumiría las funciones de la "Sección Pedagógica". Estas fueron las bases a partir de las cuales se organizaron la "Escuela Superior de Química y agricultura" la "Escuela de Agrimensura" y la "Escuela de Farmacia". De ellas derivaron las dos facultades y la escuela que estableció por decreto el PEN en 1921: la Facultad de Ingeniería, la Facultad de Química y Ciencias Naturales y la Escuela de Farmacia e Higiene subtropical.

En 1917 egresaron sus primeros 20 graduados, 10 farmacéuticos, seis agrimensores y cuatro maestros de agricultura. Desde ese año hasta 1924 terminaron con éxito su formación profesional 130 estudiantes, la mitad de ellos (65) nuevos farmacéuticos, once agrimensores, ocho ingenieros químicos, nueve ingenieros geógrafos, siete ingenieros químicos e industriales, cinco agricultores técnicos, cuatro maestros de agricultura, siete oficiales sanitaristas y 12 egresados de la escuela de pintura, 79 varones $(60,8 \%)$ y 51 mujeres $(39,2 \%)$, un notable porcentaje este último que demuestra que desde un primer momento las mujeres aprovecharon las posibilidades que habría la Universidad para el desarrollo de sus capacidades y la realización personal fuera del ámbito tradicional del hogar (Villarreal,1974). Si sumamos las titulaciones no universitarias, como las "maestras de enseñanza primaria y vocacional" de la Escuela Sarmiento, los diplomados escribanos, los egresados de la escuela nocturna para obreros fundada en 1918, y la escuela de electrotécnica y mecánica que inició sus actividades en 1920 (en total 370 egresados hasta el año citado), es probable que ese valor del 39,2\% se incremente, algo que no estamos en condiciones de determinar por el estado actual de la investigación.

Durante los primeros años de vida de la universidad tucumana la matrícula fue muy reducida en las carreras estrictamente universitarias. En 1923, por ejemplo, los alumnos inscriptos en sus tres facultades sumaban 102, a los que habría que agregar 47 anotados en los cursos preparatorios. Donde sí concurrieron un importante número de mujeres fue en la Escuela Pedagógica Sarmiento, que fue incorporada a la Universidad en el momento de su fundaciónón junto con otros institutos y reparticiones que funcionaban bajo administración provincial.

Su paso a la órbita universitaria implicó un cambio en los planes de estudio, el que tuvo como referencia el movimiento de fines del siglo XIX conocido como "The New-woman", ${ }^{29}$ de acuerdo a su directora Otilde Toro, para quien debía darse a las alumnas “[...] una preparación sólida y práctica para formar la New-Women de Tennyson", inspirador de la corriente (Valdez del Pino, 1920, p. 77). ${ }^{30}$

De todos modos, las mujeres tucumanas no limitaron su experiencia universitaria a la Escuela Pedagógica Sarmiento. Desafiando tabúes y prejuicios se inscribieron en carreras universitarias y terminaron exitosamente su formación profesional ya en el período fundacional de la Universidad. La experiencia, iniciada a fines del siglo XIX, de irrupción en el ámbito de la sociabilidad cultural -hasta entonces 
exclusivamente masculino- y en el sistema educativo formal, encontraría un espacio para desarrollarse a otro nivel.

\section{CONSIDERACIONES FINALES}

Las intervenciones de la maestra tucumana que se interesó por la participación en congresos científicos y por la continuación de estudios superiores, expresaban las preocupaciones intelectuales y culturales de una época, de la que también formaron parte las mujeres instruidas, en la que uno de los horizontes lo constituía el conocimiento científico con miras a la creación de una futura universidad provincial.

Es posible conjeturar que para muchas de estas mujeres, el magisterio constituyó una vía de entrada promisoria para obtener otros títulos (en estudios superiores por ejemplo) o bien experiencias y contactos internacionales (como la participación en congresos científicos), así como acceso a otros bienes culturales (al participar en asociaciones de esa índole). Es decir que sus expectativas excedían el trabajo en el aula y se esforzaron para lograr esas otras capacidades.

La modernización del sistema universitario argentino, frente al modelo profesionalista de Buenos Aires y Córdoba, incluía -entre otro tipo de novedades- la incorporación de la problemática educativa a la currícula universitaria, lo que implicó considerar la incorporación de las mujeres a los claustros habida cuenta de la ya importante presencia de estas en las actividades docentes. Aun así encontramos importantes diferencias entre La Plata y Tucumán, entre González y Terán quizás el primero aparezca más “moderno”, pues acepta y alienta a las mujeres en la vida universitaria, mientras el segundo insiste en formarlas como "educadoras" en el nivel primario, como educadoras de los sectores populares. Muy probablemente el ambiente tucumano y su pertenencia a la élite azucarera expliquen ese rasgo de su proyecto.

No obstante, algunas de las tucumanas instruidas deciden formarse como profesionales, "realizarse" personalmente fuera del ámbito doméstico y de su proyección "natural”, el aula. Creemos que es en ese contexto que la participación en congresos científicos latinoamericanos debe entenderse, además es necesario contrastar y analizar el aumento de participación de maestros, así como de publicaciones sobre cuestiones pedagógicas que se da en el congreso de Chile.

\section{Referencias Bibliográficas}

Acri, M. (2012), Las asociaciones y gremios docentes de la Argentina. La situación laboral, la organización y las primeras luchas (1881 - 1930) (Tesis de Maestría), Facultad Latinoamericana de Ciencias Sociales. Recuperado de: http ://repositorio.flacsoandes.edu.ec/bitstream/10469/4519/2/TFLACSO-2012MAA.pdf

Arias, A. C. (2016). "Las mujeres en la historia de la ciencia argentina: una revisión crítica de la bibliografía". Recuperado de http://trabajosycomunicaciones.fahce.unlp.edu.ar/.

Ascolani, A. (1998). "Historiadores e Historia educacional Argentina. Una mirada retrospectiva de su estado actual", Sarmiento, Anuario Galego de Historia de Educación, 2, 217- 226.

Assaf, S. (2000). La Escuela Normal de Tucumán. Reseña histórica, 1875-1950. Tucumán: Top Graph.

Barletta, A. M. (2011) "La Revista Archivos de Ciencias de la Educación: Apuntes para una o varias historias institucionales". En Archivos de Ciencias de la Educación, 5(5), pp. 17-36. Recuperado de: http://www.memo ria.fahce.unlp.edu.ar/art_revistas/pr.5425/pr.5425.pdf.

Barrancos, D. (2000). "Itinerarios científicos femeninos a principios del XX: solas pero no resignadas" en Monserrat, M. (Comp.) La ciencia en la argentina entre siglos. Textos, contextos e instituciones, Buenos Aires: Manantial.

Barrancos, D. (2000). “Inferioridad jurídica y encierro doméstico”, en Gil Lozano, V. et al, (Eds.) Historia de las mujeres en la Argentina. Colonia y Siglo XIX, Buenos Aires: Taurus

Barrancos, D. (2002). Inclusión/Exclusión. Historia con mujeres, Buenos Aires: FCE. 
Barrancos, D. (2007). Mujeres en la sociedad argentina. Una historia de cinco siglos, Buenos Aires: Sudamericana.

Billorou, M. (2016) "Mujeres que enseñan no solo en las aulas: docentes en el interior argentino en la primera mitad del siglo XX". Anuario de Historia de la Educación, vol. 17 nro. 2, pp. 57-79.

Bravo, M. C. (2008). Campesinos, azúcar y politica: cañeros, acción corporativa y vida política en Tucumán (1895-1930). Rosario: Prohistoria.

Caldo, P. (2013) "El hábito hace a la maestra. Hacia una historia de las prácticas de consumo de las mujeres dedicadas a la docencia en Argentina. 1939-1943". Navegamerica. Revista electrónica de la Asociación Española de Americanistas; Murcia; pp. 1-30.

Caldo, P. (2014) "No parecían mujeres pero lo eran. La educación femenina de las maestras, Argentina 1920-1930". Revista Historia y Sociedad; Medellín, pp. 1-30.

Demoor, M. (2003). Doncellas medievales en la poesía de Lord Alfred Tennyson: retratos del pasado como espejos del presente. Signos, 36 (54), pp. 169-176.

Di Liscia, M. y Maristany, J (Eds.) (1997). Mujeres y Estado en la argentina. Educación, salud y beneficencia. Buenos Aires: Biblos.

Fiorucci, F. y Rodríguez, L. (2018) Intelectuales de la educación y el Estado: maestros, médicos y arquitectos. Bernal: Universidad Nacional de Quilmes.

Fiorucci, F. (2012) "Las escuelas normales y la vida cultural", en: Fiorucci, F. y Laguarda, P. Intelectuales, cultura y politica en espacios regionales de Argentina. Rosario: Prohistoria.

García, S. V. (2006). Ni solas ni resignadas: la participación femenina en las actividades científico-académicas de la Argentina en los inicios del siglo XX. Cadernos pagu, 27, pp. 133-172.

Garrido, H. (1999). Educación, universidad y género. Participación de las mujeres en el espacio universitario tucumano. Tucumán: Facultad de Filosofía y Letras, Universidad Nacional de Tucumán.

Gindín, J. (2008). Sindicalismo docente en México, Brasil y Argentina. Una hipótesis explicativa de su estructura diferenciada. Revista mexicana de investigación educativa, 13 (37), pp. 351-375.

Gindín, J. (2010). “Associações e Sindicatos de Trabalhadores em Educação”. En Seminário Internacional da Rede de Pesquisadores sobre Associativismo e Sindicalismo dos Trabalhadores em Educação. Reunión llevada a cabo en Río de Janeiro, Brasil.

González, J. V. (1935) Obras Completas de Joaquín V. González, Vol. XIV, Buenos Aires: Universidad Nacional de la Plata.

Kreibohm, E. (1960). Un siglo de Cultura Provinciana. Aportaciones históricas alrededor de la vida de una institución tucumana. De la "Sociedad Sarmiento" a nuestra Universidad. Tucumán: Universidad Nacional de Tucumán.

Lavrin, A. (1997). Cambiando actitudes sobre el rol de la mujer: experiencias de los países del ConoSur a principios de siglo. Revista europea de estudios latinoamericanos y del caribe, 62, 71-92.

Lionetti, L. (2007). La misión política de la escuela pública: la formación del ciudadano de la república (1870-1916). Buenos Aires: Miño y Dávila.

Martínez Trucco, A. (2004). Acción Gremial del Magisterio de Santa Fe. Santa Fe: Editorial Universidad del Litoral.

Morgade, G. (1997). Mujeres en la educación. Género y docencia en la Argentina 1870-1930. Buenos Aires: Miño y Dávila.

Pérez Cantó, P. y Bandieri, S. (2005) Educación, género y ciudadania. Las mujeres argentinas: 1700-1943. Buenos Aires: Miño y Dávila.

Priego, N. (2011). Heroínas anónimoasde la ciencia en México: Petra Martínez, maestra. En Jacinto, L. y Scarzanella E. (Eds.) Género y ciencia en Amçerica Latina; mujeres en la academia y en la clínica (siglos XIX y XX). Madrid: Iberoamericana.

Ribeiro da Andrade, A. (2002). A terceira reuniao do Congresso Scientifico Latino-Americano: ciencia e politica. Río de Janeiro: Museu de Astronomía e Ciencias Afins. 
Richard Jorba, R. (2013). Somos el pueblo y la patria. El populismo lencinista en Mendoza frente al conflicto social y la prensa: discursos, representaciones y acciones, 1917-1919. Revista de Historia Americana y Argentina, 48 (1), pp. 11-54.

Sagasti, F. y Pavaez A. (1989). Ciencias y tecnología en América Latina a principios del siglo XX: primer congreso científico panamericano. Quipu, 6 (2), pp. 189-216.

Southwell, M. (2014) Cien años de Ciencias de la Educación: Entre los fundamentos de la pedagogía y el diálogo con el sistema educativo. Archivos de Ciencias de la Educación, vol. 8, no 8, pp. 1-32

Terán, J. B. (1964). La Universidad y la vida. Tucumán: U.N.T.

Terán, J. B. La Nueva Universidad. Tucumán, s.f.e.

Valdez del Pino, J. (1920). El Album del magisterio de la provincia de Tucumán. Tucumán: Gobierno de la provincia de Tucumán.

Vignoli, M. (2011) Educadoras, lectoras y socias. La irrupción de las mujeres en un espacio de sociabilidad masculino. La Sociedad Sarmiento de Tucumán (Argentina) entre 1882 y 1902. Secuencia, 80, pp. 41-62.

Vignoli, M. (2015a) Sociabilidad y cultura política la Sociedad Sarmiento de Tucumán, 1880-1914. Rosario: Prohistoria.

Vignoli, M. (2015b) "Trayectoria educativa y prácticas asociativas de una tucumana de entre siglos: Margarita Todd, maestra normalista”. Historia y Memoria, 11, pp. 123-149.

Villarreal, S. (1974). La Universidad que conocí. Tucumán: Universidad Nacional de Tucumán

Yannoulas, S. (1996). Educar: ¿una profesión de mujeres? La feminización del normalismo y la docencia 1870-1930. Buenos Aires: Kapelusz.

\section{Notas}

1 Biblioteca Ana Garmendia de Frías (En adelante BAGF) “Libro de Actas de la Fundación del Círculo del Magisterio", Tucumán, 14 de abril de 1906, pp. 23-24.

2 Margarita Todd, había egresado con 14 años de la Escuela Normal de Maestras en 1889. Formó parte del selecto grupo de "socias" que se incorporaron a la Sociedad Sarmiento cuando se decidió abrir la membresía a las mujeres educadas. Luego de una importante trayectoria en el ámbito educativo al frente de la Escuela Superior Alberdi y la Escuela de Graduadas Juana Manso, en 1904 y con 29 años, el Consejo General de Educación la designó como Directora de la Escuela de Ayudantes Sarmiento, cargo en el que se mantuvo hasta 1911 en que decidió su jubilación voluntaria. Además, se desempeñó como socia fundadora del Círculo del Magisterio, creado en 1905, y fue una de las delegadas enviadas al interior de la provincia para evaluar la necesidad de creación de bibliotecas populares. En esta asociación desempeñó varios cargos, uno de los más importantes fue el de Vicepresidenta en 1907, año en que se casó con José S. Tula, con quien tuvo una hija, Margarita Tula Todd, en diciembre de 1908 (Vignoli, 2015, p. 127).

3 El cuarto congreso contó con la participación de 20 países y la asistencia de más de dos mil personas, mientras que fueron presentados alrededor de 750 trabajos (Sagasti y Pavaez, 1989).

4 El primero presentó un trabajo en la Sección enghenaria, "Es o no conveniente recomendar a los gobiernos sudamericanos especial estudio de la política hidráulica, es o no el caso de formular votos de aplauso para la iniciación de los Gobiernos locales de Tucumán, Córdoba, Mendoza y San Juan? Debe o no persistir especialmente Tucumán en el camino que le han trazado ya sus progresistas gobernantes? (Ribeiro, 2002).

5 Sabino, Ignez "As leis de orden social permitem que a educacao e ilustracao da mulhr sejam equiparadas á educacao e ilustracao do homem?; Cunha Santos, María Clara "A aptidao da mulher no exercicio da educacao infantil e a razao suficiente para que os Estados the confie exclusivamente o ensino primario? Fueron algunos de estos trabajos (Ribeiro, 2002).

6 Para un balance historiográfico respecto del ingreso de esta temática dentro de los estudios de género se sugiere consultar el artículo de Ana Carolina Arias (2016).

7 El Porvenir (1882-1883) y El Tucumán Literario (1888-1896) fueron los órganos de difusión de la Sociedad Sarmiento. Allíse publicaron los trabajos de los socios y artículos y poesías de autores ya consagrados en la corriente estético-literaria dominada por el romanticismo. El análisis de estas publicaciones permitió relevar las diferentes temáticas abordadas en estas revistas, entre las que se destacan los tópicos relacionados con la discusión de innovaciones educativas en jóvenes, niños, mujeres y obreros; el papel de la juventud y su importancia en la inculcación de una conciencia cívica en la sociedad, así como propuestas de cambio social y tecnológico adaptado a las necesidades provinciales. 
8 Alumno de la Escuela Normal al momento de creación de la Sociedad Sarmiento, fue uno de los miembros más jóvenes al ingresar con 15 años. También participó en la Sociedad Amigos de la Educación y trabajó como maestro normal.

9 Hemeroteca de la Facultad de Filosofía y Letras (En adelante HFFyL) “Los derechos de la mujer”, El Porvenir, Tucumán, diciembre de 1882.

10 HFFyL, Caridad Jayme, “¿Qué es la mujer? El Tucumán Literario, Tucumán, Agosto de 1893.

11 HFFyL, Ignacio López Arriaga, "Lo que es la mujer”, El Tucumán Literario, Tucumán, 30 de octubre de 1893

12 En 1904 la Biblioteca de la Sarmiento contaba con 10.918 volúmenes; recibía 72 revistas y periódicos del país y del extranjero y se habían consultado a domicilio y en su salón de lectura 8.145 obras a lo largo del año.

13 Algunos de los conferencistas más relevantes durante este período fueron: Adrián Patroni, Joaquín Tula, Dr. Gámbara, Juan Bialet-Massé, Petronila B. de Albuernes, Juan José García Belloso, Fray Francisco Villalba, José I. Yani, Maximio Victoria, Octavio Vera, Dr. Leopoldo del Campo, Ing. Benjamín Reolín, Ing. Geógrafo J. Cuello Elías, Gustavo Wahlberg, Juan Heller, Gregorio R. Pinto, Pedro J. García, Prof. David Peña, Max Neumayer, Carlos Alberto Leuman, Dr. Carlos Rodríguez Etchart, Sr. Rodolfo Alcides Rivarola, Georges Clemencau, Ramón del Valle Inclan, Ing. Carlos Vallejo, Rafael Padilla, Arthur Rosenfeld, Genaro Sisto, Miguel F. Rodríguez, Dr. Aráoz Alfaro, Leopold Mabilleau, Dr. Aráoz Alfaro, Manuel J. Victoria, Dr. Ernesto Padilla.

14 En el mismo año la Biblioteca Alberdi tenía 370 socios, habían consultado libros en su biblioteca 14.185 personas y se habían organizado cinco conferencias.

15 Nos referimos también a las asociaciones culturales y bibliotecas populares fundadas en el interior tucumano desde mediados de la década de 1890 hasta 1915 aproximadamente: "Centro Patriótico" (1894, Concepción); "Liga Patriótica" (1898, Monteros); "Biblioteca Mitre” (1906, Monteros); "Biblioteca Popular Nicolás Avellaneda” (1911, Lules); "Biblioteca Popular 25 de mayo" (1913, La Cocha); "Biblioteca Municipal” (1913, Concepción); "Biblioteca Popular" (1912, Aguilares); "Biblioteca Avellaneda” (1914, Concepción); "Biblioteca Lucas A. Córdoba” (1913, Tafí Viejo); “Biblioteca Sáenz Peña” (1915, Alderetes); "Biblioteca Amaicha” (Tafí, 1907); "Biblioteca popular” (1912, Famaillá); "Biblioteca Popular Belgrano” (1912, Alberdi); "Biblioteca Nicolás Avellaneda” (1913, Concepción). AHT, “sección administrativa” 1894-1915.

16 Archivo Histórico de la Provincia de Tucumán, (En adelante AHT), Periódico El Orden, 16 de julio de 1904.

17 Los primeros cursos abarcaron los siguientes tópicos: "Higiene y profilaxia social" y "Alcoholismo", "Paludismo y tuberculosis", a cargo del Dr. Pedro J. García; "La versificación castellana, sus leyes y su historia”, a cargo de Ricardo Jaimes Freire; "conflictos sociales, ambiente e individuo", a cargo del Dr. Ubaldo Benci.

18 AHT, Periódico El Orden, 12 de septiembre de 1906.

19 AHT, Periódico El Orden, 12 de septiembre de 1906.

20 "El Ateneo", "Sociedad Científica Argentina", "Sociedad Luz".

21 AHT, Periódico El Orden, 12 de enero de 1907.

22 El Dr. Poviña dictó el curso "Estudio social sobre la tuberculosis"; Juan B. Terán uno de "Historia Americana” y los ingenieros Reolín y Costanti, abordaron, respectivamente, las siguientes temáticas: "Captación de aguas subterráneas" y "Desagües de fábricas de azúcar y su purificación”.

23 AHT, Periódico El Orden 9 de septiembre de 1908.

24 AHT, Periódico El Orden 9 de noviembre de 1909.

25 AHT, Periódico El Orden, 6 de mayo de 1910.

26 AHT, Periódico El Orden, 23 de julio de 1910.

27 AHT, “Sección administrativa”, vol. 376, 27 de diciembre de 1913, p. 330.

28 De hecho varias maestras y maestros del interior tucumano y de la capital elevaron notas al gobierno de la provincia a fin de obtener una beca de estudios para la carrera de Pedagogía de La Plata.

29 Es probable que las educadoras que dirigían la Escuela durante el período que pasa a la Universidad, estuvieran al tanto de la literatura inglesa y norteamericana de fines del siglo XIX y pensaran en ese perfil para las egresadas de la Escuela Sarmiento. Por otro lado sabemos que los hombres de la Generación del Centenario, como se ha dado en llamar a los fundadores de la universidad provincial, estaban imbuidos de las novedades literarias, artísticas y estéticas y que colaboraban en su difusión a través de revistas o de conferencias periódicas.

30 Este poeta inglés escribió sobre temas mitológicos y medievales, entre sus principales obras se encuentra el poema “The Princess", en el que se alude a la educación superior de las mujeres. (Demoor, 2003). 